\title{
Residual stresses in chemically vapor deposited coatings in the Ti-C-N system
}

\author{
S. EROGLU ${ }^{(1)}$ and B. GALLOIS
}

Department of Materials Science and Engineering, Stevens Institute of Technology, Hoboken, NJ 07030, U.S.A.

\begin{abstract}
Residual stresses in chemically vapor deposited monolithic and graded coatings in the Ti-C-N system were investigated as a function of substrate material and coating composition by $x$-ray diffraction $\sin ^{2} \Psi$ method. The thermal expansion coefficients (CTEs) of the graphite substrates ranged from $2.5 \times 10^{-6} \mathrm{~K}^{-7}$ to $8.6 \times 10^{-6} \mathrm{~K}^{-1}$. Titanjum nitride (CTE $9.35 \times 10^{-6} \mathrm{~K}^{-1}$ ) and titanium carbide (CTE $7.5 \times 10^{-6} \mathrm{~K}^{-1}$ ) coatings deposited on the

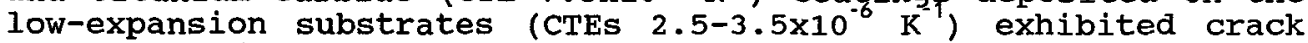
networks which accounted for low stress levels measured in the coatings. A phenomenalogical explanation of the crack patterns was given. The coatings grown on the substrates with high coefficients of thermal expansion (CTEs $7.8-8.6 \times 10^{-6} \mathrm{~K}^{-1}$ ) had no cracks. Residual stresses in the TiN coatings on these substrates were measured to be tensile. Whereas Tic coatings always exhibited compressive stresses ranging from $-54 \pm 10 \mathrm{MPa}$ to $-288 \pm 18 \mathrm{MPa}$. The $\mathrm{TiC}_{\mathrm{x}} \mathrm{N}_{y}$ coatings deposited on the substrate with a thermal expansion coefficient of $8.6 \times 10^{-6} \mathrm{~K}^{-1}$ also had compressive stresses increased with increasing $\mathrm{TiC}$ mole fraction in the $\mathrm{TiC}_{\mathrm{x}} \mathrm{N}_{\mathrm{y}}$ up to about 0.9 above which stresses decreased. The residual stresses in the top TiC layers of the graded TiN/TiC coatings with linear, parabolic and exponentional composition profiles grown on the the same substrate (CTE $8.6 \times 10^{-8} \mathrm{~K}^{-1}$ ) were measured to be compressive and about $475 \mathrm{MPa}$. Stresses in the coatings were calculated and attributed to the thermal expansion mismatch between the coating and the substrate. It was shown that the measured stresses were, in general, found to be in good agreement with the calculated ones.
\end{abstract}

\section{Introduction}

Nearly all vapor-deposited coatings are found to be in a state of residual or internal stress. Internal stresses can affect the integrity of the coating either by producing cracks (tensile stress) or by buckling (compressive stress). They can also influence the fracture, wear and fatigue behavior and the corrosion resistance of the coating-substrate composite. Therefore, it is important to understand the levels and origins of internal stresses in the coatings.

Whereas stresses in thin films deposited by physical vapor deposition methods have been the subject of extensive research, there is a scarcity of published reliable information on the internal stresses in coatings synthesized by chemical vapor deposition (CVD) technique. The present study was undertaken in order to investigate the effect of

(1) Address for correspondence: TUBITAK, Marmara Research Center, Materials Research Division, P.O. Box 21, Gebze-Kocaeli, Turkey 
substrate and the coating composition on internal stresses in the deposits grown by CVD in the Ti-C-N system and on the coherence (e.g. the absence of cracks) of the coatings.

\section{Experimental Details \\ 2.1. Chemical Vapor Deposition}

The depositions were carried out in a computer-controlled hot-wall chemical vapor deposition reactor at $10.7 \mathrm{kPa}$ (80 Torr). The reactant gas ratios of $200 \mathrm{H}_{2}: 200 \mathrm{~N}_{2}: 20 \mathrm{TiCl}_{4}(\mathrm{sccm})$ for TiN and $600 \mathrm{H}_{2}: 50 \mathrm{CH}_{4}: 20 \mathrm{TiCl}$ (sccm) for Tic were chosen to yield stoichiometric deposits. Chemical vapor deposition of $\mathrm{TiC}_{\mathrm{x}} \mathrm{N}_{\mathrm{y}}$ coatings was carried out at $1400 \mathrm{~K}$ and a total flow rate of $670 \mathrm{sccm}$ for a growth time of 75 minutes. The experiments were divided into two series. In the first series, the total $\mathrm{CH}_{4}+\mathrm{N}_{2}$ flow rate was held constant at $370 \mathrm{sccm}$, whereas it was equal to $175 \mathrm{sccm}$ in the second one. The ratio of $\mathrm{CH}_{4}$ to $\mathrm{CH}_{4}+\mathrm{N}_{2}\left(\mathrm{X}_{\mathrm{CH}}\right)$ was varied from 0 to 1 for constant $\mathrm{TiCl}_{4}$ flow rate $(20 \mathrm{sccm})$ and constant $\mathrm{H}_{2}$ flow rates. The morphologies of the $\mathrm{TiC}_{x} \mathrm{~N}_{y}$ coatings grown at a $\mathrm{CH}_{4}+\mathrm{N}_{2}$ flow rate of 370 sccm were whiskery and rough. The $\mathrm{TiC}_{x} \mathrm{~N}_{y}$ coatings deposited at a $\mathrm{CH}_{4}+\mathrm{N}_{2}$ flow rate of $175 \mathrm{sccm}$, however, exhibited smoother surface morphologies. The deposition of graded TiN/TiC coatings were carried out by continously varying the $\mathrm{X}_{\mathrm{CH} 4}$ ratio in the range $0-1$ at a constant $\mathrm{CH}_{4}+\mathrm{N}_{2}$ flow rate of $175 \mathrm{sccm}$. Detailed studies of the chemical vapor deposition of $\mathrm{TiC}_{\mathrm{x}} \mathrm{N}_{y}$ coatings and the graded coatings were published elsewhere [1]. Texture analyses on these coatings were reported in Ref. [2] .

The substrates were rectangles $2 \mathrm{~cm} \times 1 \mathrm{~cm}$, $1 \mathrm{~mm}$ thick, cut from several types of graphite. The properties of the graphites are listed in Table I. The main difference among these materials is in the thermal expansion coefficient which ranges from $2.5 \times 10^{-6} \mathrm{~K}^{-1}$ to $8.6 \times 10^{-6} \mathrm{~K}^{-1}$. TiN and TiC coatings were grown on all the substrates listed in the Table I in order to investigate the effect of the substrate on the internal stress. The graphite substrate with a thermal expansion coefficient of $8.6 \times 10^{-6}$ $\mathrm{K}^{-1}$ was used for the $T \mathrm{TC}_{x} \mathrm{~N}_{y}$ monolithic coatings with $\mathrm{C} / \mathrm{C}+\mathrm{N}$ ratios in the range $0-1$ and for the graded TiN/TiC coatings.

Table I- Properties of the graphite substrates

\begin{tabular}{|c|c|c|c|c|c|}
\hline Substrate & $\begin{array}{l}\text { Thermal Exp. } \\
\text { Coefficient } \\
\left(\times 10^{-6} \mathrm{~K}^{-1}\right)\end{array}$ & $\begin{array}{l}\text { Tensile } \\
\text { Strength } \\
\text { (MPa) }\end{array}$ & $\begin{array}{l}\text { Compressive } \\
\text { Strength } \\
\text { (MPa) }\end{array}$ & $\begin{array}{l}\text { Young's } \\
\text { Modulus } \\
\text { (MPa) }\end{array}$ & $\begin{array}{l}\text { Porosity } \\
\text { (\%Vol.) }\end{array}$ \\
\hline $\begin{array}{l}\text { TS }-1792^{a} \\
\text { Vitr. Carbon } \\
\text { AXZ-5Q } \\
\text { AXM-5Q } \\
\text { AXF-5Q } \\
\text { ACF-10 } \\
{ }^{c}\end{array}$ & $\begin{array}{l}2.5 \\
3.5 \\
7.8 \\
8.2 \\
8.4 \\
8.6\end{array}$ & $\begin{array}{l}27 \\
- \\
34.5 \\
48.3 \\
65.5 \\
69\end{array}$ & $\begin{array}{l}66.5 \\
147-196 \\
97 \\
124 \\
145 \\
186\end{array}$ & $\begin{array}{l}9.6 \\
22 \\
9 \\
10.3 \\
11 \\
11\end{array}$ & $\begin{array}{l}- \\
0 \\
28 \\
23 \\
20 \\
21\end{array}$ \\
\hline
\end{tabular}

a: Supplied by Union Carbide Corp.

b: Atomergic Chemetals corp.

c:Poco graphite, Inc.

\subsection{X-ray diffraction measurements of internal stress and lattice parameter}

X-ray analyses were performed on a General Electric XRD-6 parafocusing diffractometer equipped with a copper tube and $N_{i} K_{B}$ filter. $A$ more precise description of the $X$-ray diffraction device is given elsewhere [3]. The lattice parameter of a stress-free silicon briquette was measured to be equal to $0.543040 \pm 0.000006 \mathrm{~nm}$, in excellent 
agreement with the the published value of $0.54301 \mathrm{~nm}$ [4]. The residual stress measured in the silicon powder was equal to $3 \mathrm{MPa} \pm 12 \mathrm{MPa}$, which is very small as expected from the powder.

Internal stresses in the coatings were measured by the well-known $\sin ^{2} \Psi$ method [5], where $\Psi$ is the angle between the crystal planes and the sample surface. The $\mathrm{K}_{\alpha 1}(511,333)$ or $(422)$ reflections were used for the stress measurements. The measured profiles of the peaks were corrected for angular dependence of the Lorentz polarization and absorption factors. The peak position was then determined by fitting a parabola to the top part of the profile.

Precision lattice parameters perpendicular to the plane of the coating were measured using the $K_{\alpha 1}$ and $K_{\alpha 2}$ reflections of the $(511,333)$, (422), (420) and (331) crystal planes. The peak positions were determined by the method used for the stress measurements. The NelsonRiley analysis [6] was applied to obtain the true lattice parameter.

\section{Results and Discussion}

The internal stresses in CVD coatings consist of intrinsic stress and extrinsic stress. Intrinsic stress is the stress induced during growth and arises from sources such as impurity incorporation and structural defects. Intrinsic stress is usually low in chemically vapor deposited coatings because of the annealing effect of this process which is carried out at high temperatures (generally $1300 \mathrm{~K}$ ). Extrinsic stress results from the thermal expansion (or contraction) mismatch between a coating and its substrate. If the coefficients of thermal expansion differ, cooling from the deposition temperature $\left(\mathrm{T}_{\mathrm{CVD}}\right)$ to room temperature $\left(T_{R}\right)$ will produce stress. This stress contribution known as thermal stress is predominant over the intrinsic stress for the chemically vapor deposited coatings.

The thermal stresses in a coating/substrate system can be calculated by using the theory of elasticity [7]:

$$
\sigma_{j}=E_{i}\left(\epsilon-\alpha_{i} \Delta T\right) /\left(1-v_{i}\right)
$$

where $\epsilon$ is the strain common to the substrate/coating composite, $\alpha$ is the coefficient of thermal expansion, $\sigma$ is the stress, $\Delta \mathrm{T}$ is the temperature change $\left(T_{R}-T_{\text {cVD }}\right), E$ is Young's modulus and $v$ is Poisson's ratio. The subscript refers to the coating or the substrate. The strain is given by

$$
\epsilon=\frac{\sum E_{i} \alpha_{i} t_{i} \Delta T /\left(1-v_{i}\right)}{\sum E_{i} t_{i} /\left(1-v_{i}\right)}
$$

where $t$ is thickness. For a thin coating on a thick substrate $\left(t_{c} / t_{s}<<\right.$ 1), the stress in the coating is given by:

$$
\sigma_{c}=E_{c}\left(\alpha_{s}-\alpha_{c}\right) \Delta T /\left(1-v_{c}\right)
$$

Eq. 3 is the conventional formula employed in the literature on thin films for calculating thermal stresses in the coatings.

Above equations indicate that the thermal stress is influenced by the differences in properties of the substrate and the coating and thickness of the coating and substrate. The calculations of thermal stresses in $\mathrm{TiC}_{\mathrm{X}} \mathrm{N}_{\mathrm{y}}$ and graded TiN/TiC coatings required a knowledge of the coefficient of thermal coefficient and Young's modulus as a function of composition. Since such information is not available, it was assumed that the properties change linearly with the TiC mol fraction in $\mathrm{TiC}_{\mathrm{X}} \mathrm{N}_{\mathrm{y}}$. They were calculated using the following values given for pure TiN and TiC: $\mathrm{E}_{\mathrm{TiC}}=450 \mathrm{MPa}$, ETiN=250 $\mathrm{MPa}, \alpha \mathrm{TiC}=7.5 \times 10^{-6} \mathrm{~K}^{-1}$ and $\alpha_{\mathrm{TiN}}=9.35 \times 10^{-6} \mathrm{~K}^{-1}$. The 
Poisson's ratio is equal to 0.2 for all the materials investigated here.

\subsection{Effect of substrate}

The TiN and TiC coatings deposited on the substrate with low coefficients of thermal expansion (TS-1792 and vitreous carbon) exhibited low levels of stresses. The measured stresses in Tic coatings ranged from +66 $\mathrm{MPa}$ and $-92 \mathrm{MPa}$. TiN coatings exhibited tensile stresses of the order of $40 \mathrm{MPa}$. This behavior is explained as follows: since the deposition process takes place at high temperatures, the major source of residual stress arises from the difference between the thermal expansion coefficients of the substrate and the coating. The thermal stress which developed during the cooling stage from the deposition temperature to room temperature is calculated to be tensile and of the order of 2000 MPa. Such high tensile stresses caused the coatings to crack and the thermal stresses developed during the cooling stage were relieved. It was observed that all the coatings deposited on the substrate with the low coefficients of thermal expansion exhibited crack networks.

The TiN and Tic coatings deposited on graphites with high thermal expansion coefficients $\left(7.8-8.6 \times 10^{-6} \mathrm{~K}^{-1}\right)$ exhibited no cracks because the thermal mismatch between the coating and the substrate was small and of the order of $15 \%$. Table II shows the results of stress analyses for the TiN and Tic coatings deposited at $1425 \mathrm{~K}$. As seen from the table, the sign of the stresses agrees with the calculations obtained from Eq. 3 . The levels of stresses are, however, lower than the calculated ones. This result suggests that stress relaxation occurred in the substrate or the coating during cooling stage. A partial delamination of the coating could be responsible for such a relaxation.

Table II- Internal stresses in TiN and TiC coatings deposited at $1425 \mathrm{~K}$ on graphite substrates with high coefficients of thermal expansion.

Thermal Expansion Coefficient of the Substrates

\begin{tabular}{lllll}
$\begin{array}{c}\text { Substrates } \\
\left(\times 10^{-6} \mathrm{~K}^{-1}\right)\end{array}$ & Measured & Calculated & Measured & calculated \\
\hline 7.8 & $+128 \pm 13$ & +416 & $-126 \pm 21$ & -190 \\
8.2 & $0 \pm 15$ & +278 & $-54 \pm 10$ & -440 \\
8.4 & $+141 \pm 21$ & +208 & $-288 \pm 18$ & -560 \\
8.6 & $0 \pm 12$ & +140 & $-162 \pm 5$ & -686 \\
\hline
\end{tabular}

\subsubsection{Crack morphology}

Fig.1 (a) shows a SEM micrograph of a typical coating surface which contains intersecting crack lines. The dominant feature of the micrograph is that the crack Iines meet each other approximately at an angle of $90^{\circ}$ and do not cross. The origin of this crack pattern can be explained qualitatively. The cracks form perpendicularly to the largest stresses in their vicinity. Once a crack has formed the stress perpendicular to the crack line is relieved. Any remaining stress near the crack must be in a direction parallel to it. If another crack that has started at any other place in the coating moves near the first crack, the second crack will begin to move more and more perpendicularly to the first crack line because the stress parallel to the first crack increasingly becomes smaller. If the second crack continues to propagate, it will meet the first one at an angle of $90^{\circ}$.

Fig. 1(b) shows a SEM micrograph of a crack junction at high 
magnification. The clear sharp breaks of grain boundaries indicate that cracks did not form during chemical vapor deposition. The micrograph also shows cracks opening perpendicular to the coating surface indicating that tensile stress was in the plane of the coating. The crack lines follow grain boundaries suggesting intergranular fracture formation.
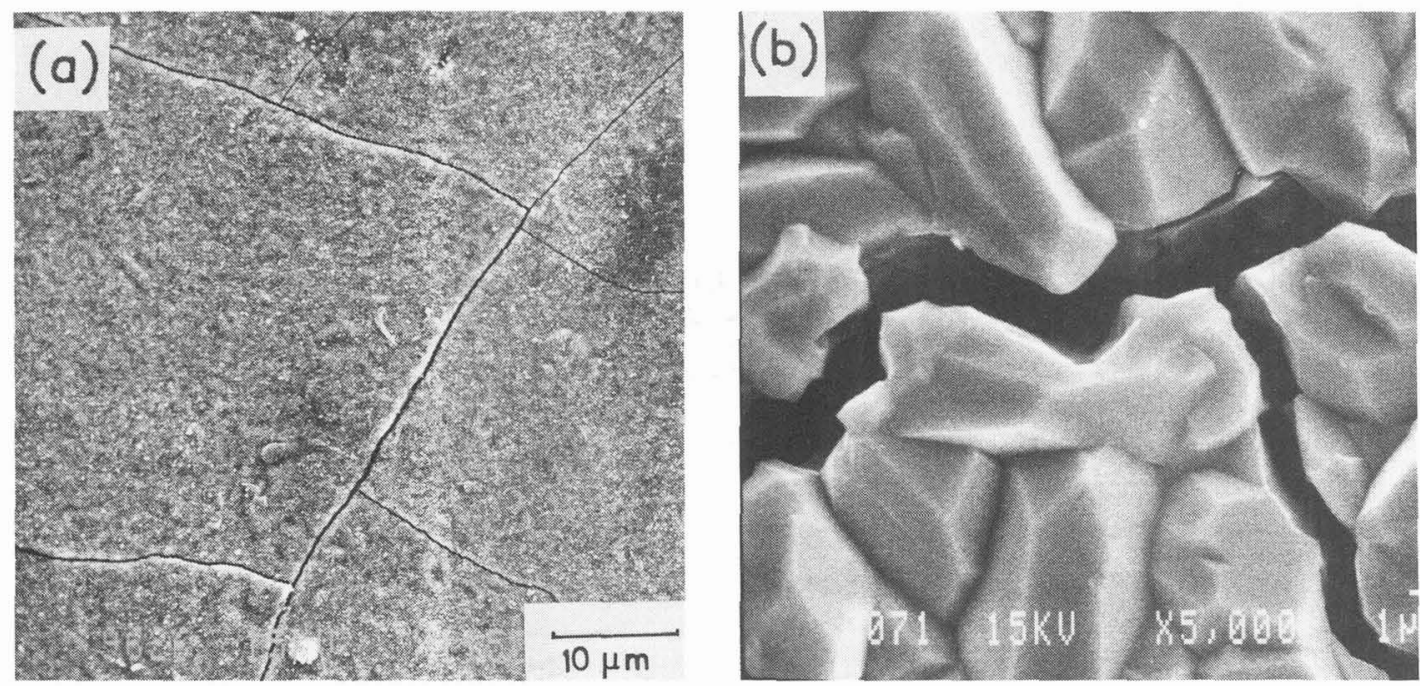

Fig. 1- scanning electron micrographs of the surface morphologies of the TiN coatings grown on the low expansion substrate (CTE $2.5 \times 10^{-6} \mathrm{~K}^{-1}$ ), at magnifications of (a) $1500 \mathrm{X}$ and (b) 5000X, showing crack networks.

\subsubsection{The effect of stress on lattice constant}

The analysis on the $(511,333),(422),(420)$ and (331) reflections revealed that the coatings exhibited sharp diffraction profiles and good separation of the $K_{\alpha 1}$ and $K_{\alpha 2}$ peaks, indicating that the coatings had small microstrains and good crystalline structures and no significant plastic deformation took place in the coatings during cooling from the deposition temperature to room temperature.

Lattice parameters perpendicular to the plane of the coating obtained from the Nelson-Riley analysis were plotted against residual stresses for the TiN coatings grown on the substrate with a coefficient of thermal expansion of $2.5 \times 10^{-6} \mathrm{~K}^{-1}$. It can be seen from Fig. 2 that as residual tensile stress increases, the lattice parameter perpendicular to the plane of the coating decreases because of the Poisson's ratio effect. The solid line with a slope of $-6.1 \times 10^{-7} \mathrm{~nm} / \mathrm{MPa}$ was obtained from a linear least-square fit to the data. The dashed-dotted line with a slope of $-6.8 \times 10^{-7} \mathrm{~nm} / \mathrm{MPa}$ was calculated by the following equation for isotropic plane stress in the coating [8]:

$$
\sigma=\frac{E}{2 v} \frac{\left(a_{0}-a\right)}{a_{0}}
$$

where $E$ and $v$ are the Young's modulus and the Poisson's ratio of the coating, and $a_{0}$ and $a$ are the unstrained bulk lattice parameter and the strained lattice parameter of the coating, respectively.

The stress-free lattice parameters were deduced by substituting $\sigma=0$ 
in the linear least-square fit to the data. The value deduced is 0.42400 $\mathrm{nm}$ which is in excellent agreement with the lattice parameter of stoichiometric titanium nitride, which is equal to $0.4240 \mathrm{~nm}$ [9].

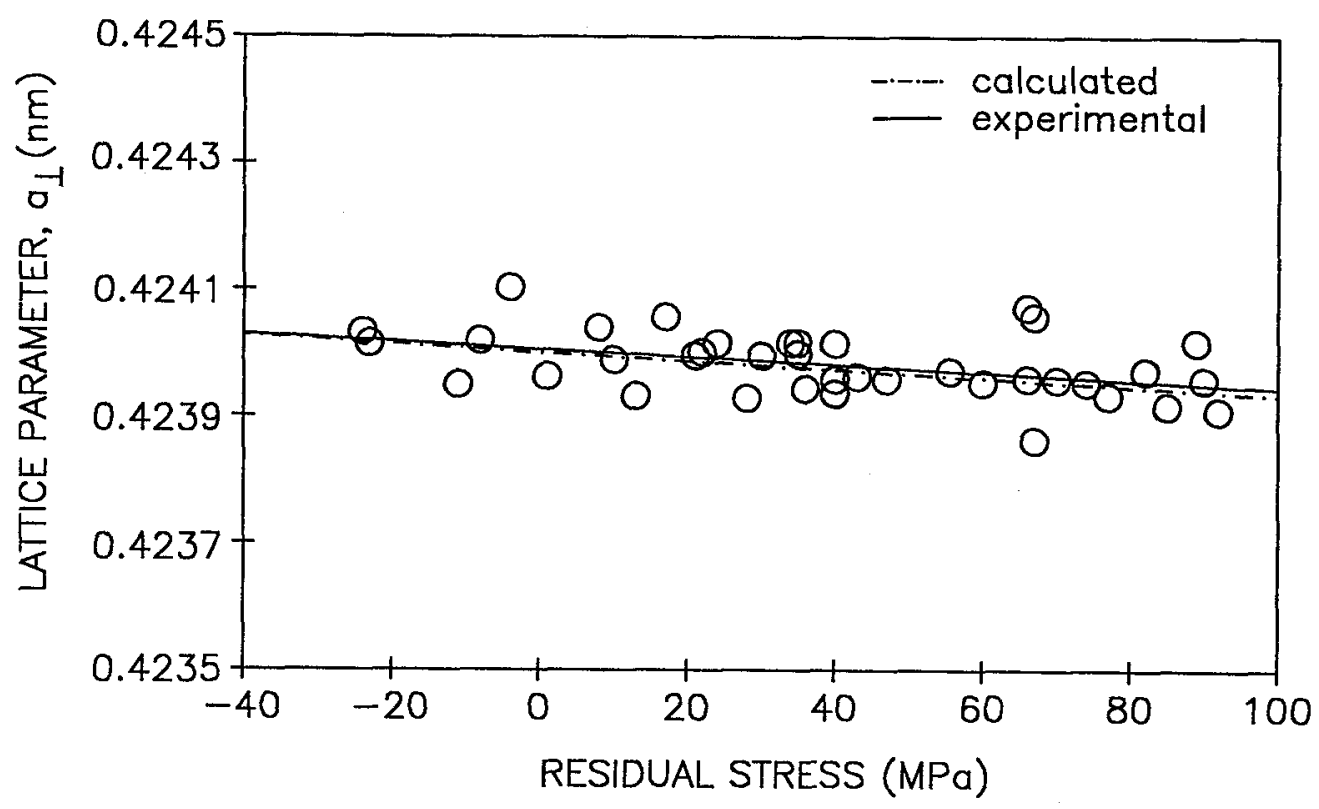

Fig. 2- The effect of residual stress measured in TiN coatings on the lattice constant perpendicular to the plane of the coating.

\subsection{Effect of deposit composition}

Fig. 3 shows the variation of internal stresses in $T i C_{x} N_{y}$ coatings with the composition of deposits. Stresses in pure TiN coatings were measured to be almost zero. The compressive internal stresses increased with increasing TiC content in the film up to a TiC mole fraction of about 0.90 above which stresses decreased to $-270 \mathrm{Mpa}$. In order to explain this behavior, theoretical stresses were calculated using Eqs. 1 and 2. The calculated stresses are also plotted along with the measured ones in Fig. 3. In the TiN coatings, the calculated tensile stresses are of the order of $240 \mathrm{MPa}$ and higher than those measured. Since the coating grown at a nitrogen flow rate of $370 \mathrm{sccm}$ has whiskery features, such open structure could not sustain a mechanical force and the stress decreased to zero. However, the TiN deposit prepared at 175 sccm is dense and no cracks were observed in this coating. The calculated stresses in coatings with a TiC content ranging from 0.50 to 0.8 are in good agreement with the measured ones. The measured stresses at 0.91 and 0.97 are higher than the calculated ones. The reason for this behavior is not known. In nearly pure and pure Tic coatings, the calculated and measured stresses are in good agreement with each other.

Fig. 4 shows stress plots for the functional layer of TiC deposited on top of the graded TiN/TiC coatings. The internal stresses in the TiC layers were measured to be compressive. They were equal to $-440,-475$ and $-500 \mathrm{MPa}$ for the coatings with exponentional, linear and parabolic composition profiles, respectively. As can be seen from the plots, all the data points lie on straigth lines, indicating that there were no 
stress gradients in the coatings. The theoretical stresses in the TiC layers were calculated using Eqs. 1 and 2 . It was found that the calculated stresses were in good agreement with the measured ones (Fig.4).

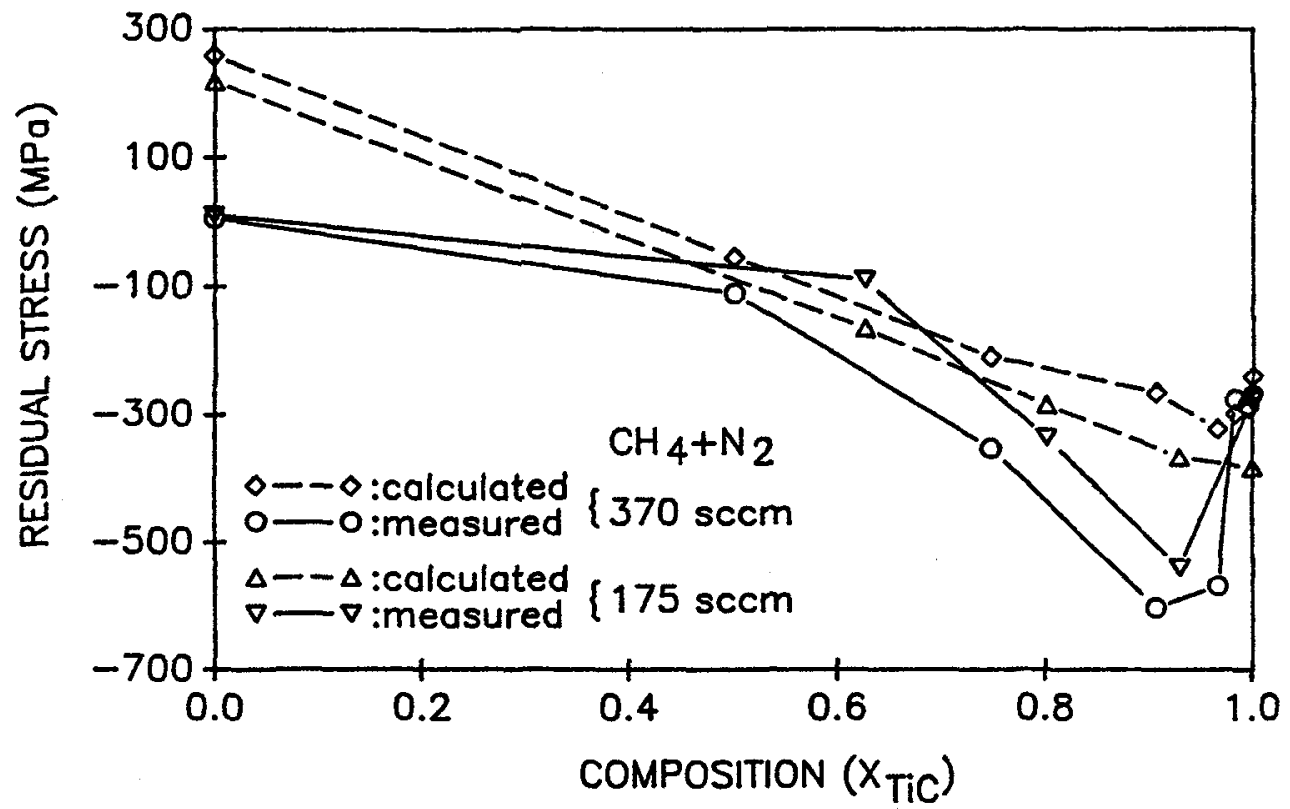

Fig. 3- Variation of residual stress in the monolithic $T i C_{x} N_{y}$ coatings as a function of $\mathrm{TiC}$ mole fraction in the $\mathrm{TiC}_{\mathrm{x}} \mathrm{N}_{\mathrm{y}}$.

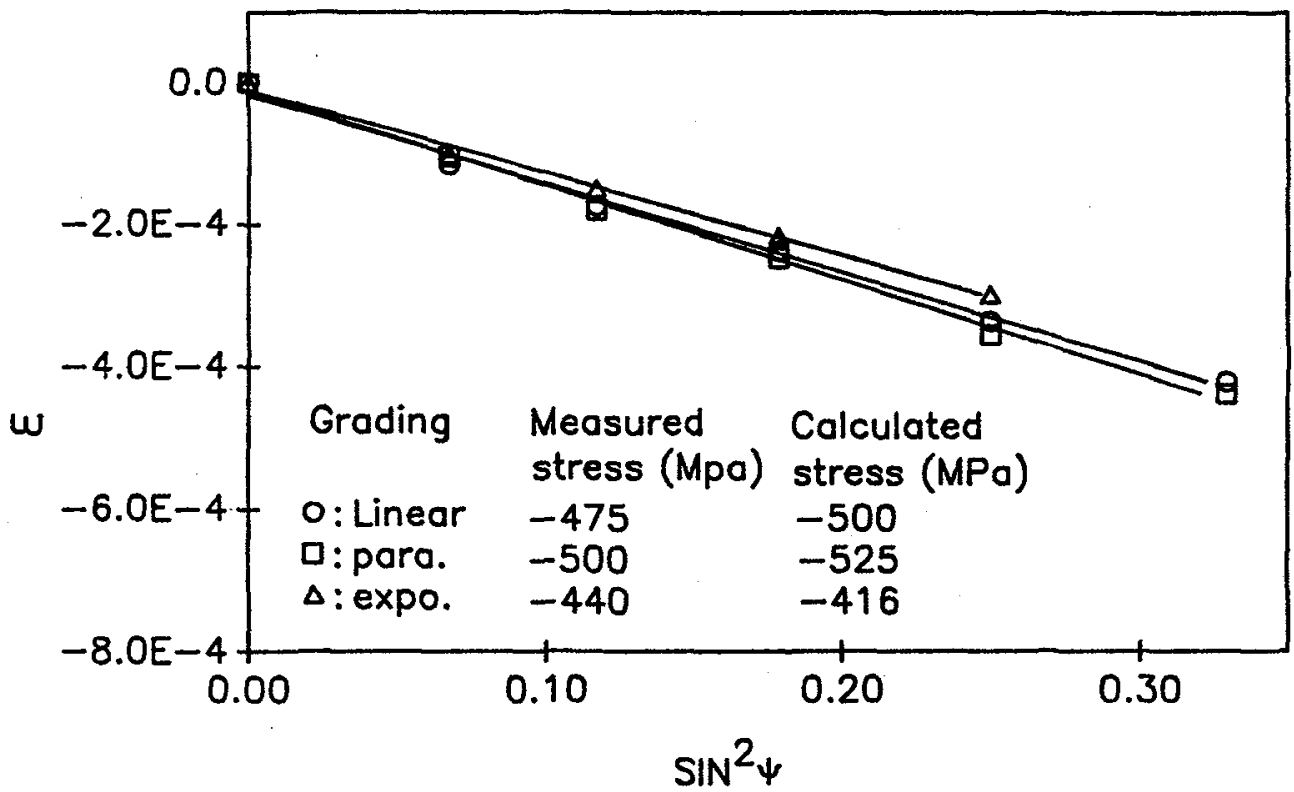

Fig. 4- X-ray stress plots for the graded coatings. Internal stresses were measured in the TiC top layers of the graded TiN/TiC coatings. 


\section{Conclusions}

(1) TiN and TiC coatings grown on graphite substrates with low coefficients of thermal expansion exhibited extensive crack networks which relieved thermal stresses.

(2) No crack networks were observed in the coatings deposited on graphites which have coefficients of thermal expansion close to those of TiN and TiC. The tensile and compressive stresses were obtained in TiN and TiC coatings, respectively. The low levels of the residual stresses measured in these coatings could be due to the unknown sources of relaxation that might occur during the cooling stage.

(3) Compressive stresses in $\mathrm{TiC}_{\mathrm{x}} \mathrm{N}_{y}$ coatings increased with increasing TiC mole fraction up to about 0.90 above which stresses decreased. The TiC layers of the graded coatings also exhibited compressive stresses.

(4) The calculated thermal stresses, in general, agreed with the measured ones.

\section{Acknowledgements}

The authors gratefully acknowledge the partial support of the Army Research office, Division of Materials Science, under contract DAAG29-85K-0124, and the New Jersey Advanced Technology Center for Surface Engineered Materials. S. Eroglu was partially supported by the Ministry of Education of the Republic of Turkey.

\section{References}

[1] Eroglu S. and Gallois B., Surf. Coat. Technol., 49(1991) 275.

[2] Eroglu S. and Gallois B., Proc. 9th European Conf. Chemical Vapor Deposition, Tampere, Finland, 23-27 August 1993.

[3] Eroglu S., Ph. D. Thesis, Stevens Institute of Technology, Hoboken, New Jersey, 1991.

[4] ASTM Card No. 5-065, American Society for Testing and Materials, Philadelphia, PA.

[5] Hilley M. E., Residual Stress Measurement by X-ray Diffraction, SAE J784a, Handbook Supplement, Society of Automotive Engineers, Warrendale, PA, 1971.

[6] Barret C. S. and Massalski T. B., structure of Metals, Pergamon, Oxford, 3rd edn., 1980, p. 204.

[7] Gatewood B. E., Thermal Stress, McGraw Hill, New York, 1957, pp.1-6.

[8] Chopra K. L., Thin Film Phenomena, McGraw Hill, New York, 1969, pp. 266-327.

[9] Joint Committe on Powder Diffraction Standards, File No. 6-0642, Philadelphia, PA. 